\title{
Determination of Antiphospholipid Antibody Levels Among Patients with Acute Myocardial Infraction in Khartoum State (Time)
}

\author{
Mohamed Hilmi ${ }^{1}$, Ehab Mohamed ${ }^{2,3}$, Albara Ahmed ${ }^{3}$, Sahar Elderdiri Gafar Osman ${ }^{3}$ \\ ${ }^{1}$ Faculty of Medical Laboratory Science, National University, Khartoum, Sudan \\ ${ }^{2}$ Faculty of Medical Laboratory Sciences, Dongola University, Dongola, Sudan \\ ${ }^{3}$ Medical Laboratory Science Program, Alfajr College for Science and Technology, Khartoum, Sudan
}

Email address:

mohamedhilmi308@gmail.com (M. Hilmi), eelmadenah@gmail.com (E. Mohamed), albaraa1983@yahoo.com (A. Ahmed)

\section{To cite this article:}

Mohamed Hilmi, Ehab Mohamed, Albara Ahmed, Sahar Elderdiri Gafar Osman. Determination of Antiphospholipid Antibody Levels Among Patients with Acute Myocardial Infraction in Khartoum State (Time). International Journal of Cardiovascular and Thoracic Surgery.

Vol. 7, No. 5, 2021, pp. 50-54. doi: 10.11648/j.ijcts.20210705.11

Received: May 26, 2021; Accepted: June 17, 2021; Published: October 12, 2021

\begin{abstract}
Background: Antiphospholipid antibodies (Anti PLP Antibody) are a group of autoimmune antibodies that targeting an individual's own proteins in an autoimmune response against phospholipids. Which released from plasma membrane to make prothrombinase complex and provide suitable environment for biological activity. In Antiphospholipid syndrome anti PLP antibodies attacks phospholipid in surface of plasma membrane and release PLP into the circulation which can activate coagulation cascade and form thrombi that leads to myocardial infraction (MI). Objectives: The current study was aimed to assess the antiphospholipid antibodies among patients with acute myocardial infraction in Khartoum state 2021 and compared to normal adult healthy control. Methods: An analytical case and control study was conducted in Yastapshiron hospital lab in Khartoum states laboratory in the period from from October 2020 to January 2021 on a total of 50 patients with acute MI (according to protocol/criteria/ scoring systrm,...) as case group and compared with another 50 healthy adults as control group, for both groups serum antiphospholipid was assessed using ELISA manual (AESKU), data were collected and then analyzed using SPssDD version. Result: from the study; the gender distribution was 35 male and 15 female among case group with age of 61.1 year. Among case group; 3 patients $(6 \%)$ showed positive antiphospholipid while the remaining 47 (94\%) was negative, the antiphospholipid antibodies mean concentration was significantly higher among case compared to the control $0.293 \pm 0.17$ and $0.226 \pm 0.15$ (unit) respectively, P.value was 0.042 . It was found space in age the lowest age was 35 and highest age was 94 and the correlation was 0.154 .
\end{abstract}

Keywords: Antiphospholipid Antibody (Anti PLP Antibody), Acute Myocardial Infraction (Acute MI), Coagulation Cascade

\section{Introduction}

Antiphospholipid antibody syndrome (APS) is a group of disorders related to both venous and arterial thromboembolic disease, which result in hypercoagulable state and increase the frequency of acute myocardial infarction (AMI) mainly in childhood. So far, the anticoagulants management is critical [1-3]. These antibodies are directed against proteins that bind to plasma membranes phospholipids. APS can be classified as a primary or secondary disorder and women is more frequently affected, especially those with complicated pregnancy such as miscarriage, stillbirth, or preterm delivery. APS Laboratory classification requires the presence of at least one of the following: lupus anticoagulant, moderate to high levels of anticardiolipin antibodies (aCL), and/or moderate to high levels of anti- $\beta_{2}$ glycoprotein 1 antibodies (Anti- $\beta_{2}$ GP1) [4].

The phospholipid on activated plasma platelets gives a catalytic surface on which the "tenase" complex (factor IXa and factor VIIIa) and the "prothrombinase" complex (factor $\mathrm{Xa}$ and factor $\mathrm{Va}$ ) can be worked. The formation of the platelet procoagulant surface involves the exposure of 
anionic phospholipids such as phosphatidylserine, which is associated with macrovesicles shedding from the activated platelet membranes Also, tissue-factor, which needed for starting the extrinsic pathway of coagulation cascade, depend on the phospholipids for optimal biological activity. Therefore, that dependency explains the prolongation of clotting tests depend on phospholipids amongst patients with phospholipid directed antibodies as found in lupus anticoagulants [5]. The clinical presentation of APS includes thrombosis and/or fetal loss or pregnancy morbidity in patients with antibodies against antiphospholipid (aPL) and these antibodies represent the major common causes of acquired thrombophilia and, Despite, there were a lot of research related to aPL there is no unified mechanism that needed to explain their prothrombotic activity; and these may be due to the heterogeneity of aPL and they may influence multiple pro- and/or antithrombotic pathways. Antiphospholipid antibodies are directed primarily against phospholipid binding proteins such as $\beta_{2}$-glycoprotein 1 ( $\beta_{2}$ GPI) and also antibodies directed to prothrombin are well defined. The lupus anticoagulant (LA) detection, which leads to prolongation of phospholipid-dependent anticoagulation tests, and/or anticardiolipin and anti- $\beta_{2}$-glycoprotein 1 antibodies are represents the main laboratory diagnosis of aPL. For thrombotic APS There were no definite anticoagulation therapy, and some reports suggest caution in the use of direct oral anticoagulants in patients with APSassociated thrombosis. the low molecular weight heparin and aspirin are most recommended for obstetrical APS [5]. Studies reported a strong association between LA and patients with VTE and these suggests useful of testing for LA in patients with VTE. There was no association between the presence of ACLA and VTE, that is due to presence of the high frequency of positive ACLA assays in patients without VTE. [6].

According to the presence of thrombosis of arterial or venous origin There are different recommended anticoagulation strategies in APS patients. oral anticoagulation with vitamin $\mathrm{K}$ antagonists is the treatment of choice and is useful [7].

This study was aimed to determine the antiphospholipid antibodies in patient with acute myocardial infraction and compared to normal control.

\section{Material and Method}

This study was designed as case and control study. The Study was conducted in Yastabshiroon hospital in Khartoum states. The study was conducted in hundred (100) individuals, fifty (50) patients with acute myocardial infraction and fifty (50) were healthy individuals as control healthy. All patients with acute myocardial infraction were included in this study. All patients with chronic myocardial infraction, and under anticoagulant or Aspirin drugs were excluded from the study. This study was included 100 sample. Fifty (50) of this sample collected from patient with acute myocardial infraction and fifty (50) samples were collected from healthy people as control, sample were collected From October 2020 to January 2021.

Three $\mathrm{ml}$ of venous blood were collected by using disposable syringe and poured into plain container, immediately centrifuge and serum separate. Data were analyzed by statistical package for social science Statistical Package for the Social Sciences) (SPSS), version 16. Qualitative date was presented as mean \pm SD. Association between qualitative variable was tested using person chi scare (x2) and Fishers exact P.value. ELISA Kits had been performed for each sample using AESKU kits manual. Device of ELISA, The microplate by device the Thermo Scientific MultiskanEXmodel2008 was applied. Concentrated reagent was diluted, the concentrated sample buffer was diluted 1:5 with distilled water. The concentrated washed buffer was diluted 1:50 with distilled water.

The serum samples were diluted 1:101 with sample buffer (1x). Then $100 \mu \mathrm{l}$ of sample and buffer of each well was added and incubated for 30 minutes at 20-32c. The wells were washed $3 x$ with $300 \mu 1$ with washing buffer. and then 100 $\mu l$ of conjugate was pipetted into each well and Incubatedfor 30 minutes at 20-32c. and again the well washed $3 x$ with $300 \mu \mathrm{l}$ washing buffer. then $100 \mu \mathrm{l}$ of TMB substrate was pipetted into each well. and then incubated 30 minutes at 2032c. then e $100 \mu$ l of stop solution was pipetted in to each well. and incubated 5 minutes minimum. then plate was agitated carefully for $5 \mathrm{sec}$. and finally absorbance was readed at $450 \mathrm{~nm}$.

\section{Results}

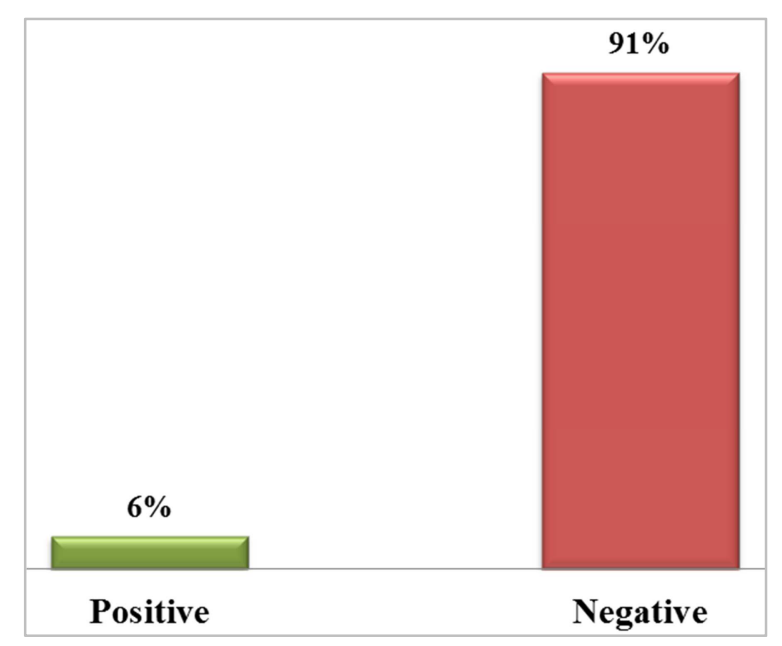

Figure 1. Percentage of anti-PLP antibodies among cases.

The result was found in Fifty (50) case have antiphospholipid antibody in acute myocardial infraction and fifty (50) healthy individual group had been selected as show in Table 1 . in this study the percent of positive was $6 \%$ have antiphospholipid and the negative was $94 \%$ as show in Table 2 , and the mean concentration of was significant, case $0.293 \pm 0.172$ and the control $0.226 \pm 0.157$ the p-value 0.042 as show in Table 3, the cases include 35 male and 15 female 
as show in Table 4 and the mean of age was 61.12as show in Table 5 is was found space in age the lowest age was 35 and highest age was 94 and the correlation was 0.154 . As show in Figure 4.

Table 1. Frequencies of cases and controls.

\begin{tabular}{lll}
\hline Status & Frequency & Percent \\
\hline Case & 50 & 50. \\
Control & 50 & 50. \\
Total & 100 & 100.0 \\
\hline
\end{tabular}

Table 2. Frequencies of positive and negative values of Anti-PLP Antibodies of groups under study.

\begin{tabular}{lll}
\hline Interpretation & Frequency & Percent \\
\hline Positive & 6 & 6.0 \\
Negative & 94 & 94.0 \\
Total & 100 & 100.0 \\
\hline
\end{tabular}

Table 3. Relation between mean of Anti-PLP Antibodies among groups under study.

\begin{tabular}{llll}
\hline Independent sample T-test & Status & N & Mean \pm SD \\
\hline Concentration of Anti-PLP & Case & 50 & $.293 \pm 0.172 \mathrm{u} / \mathrm{ml}$ \\
Antibodies & Control & 50 & $.226 \pm 0.157 \mathrm{u} / \mathrm{ml}$ \\
\hline
\end{tabular}

$\mathrm{p}$-value $=0.042$

Table 4. Relation between mean of Anti-PLP Antibodies and gender among cases.

\begin{tabular}{llll}
\hline Independent sample T-test & Gender & N & Mean \pm SD \\
\hline Concentration of Anti-PLP & Male & 35 & $.29657 \pm 0.176$ \\
Antibodies & Female & 15 & $.28547 \pm 0.168$ \\
\hline
\end{tabular}

$\mathrm{p}$-value $=0.837$

Table 5. Relation between mean of Anti-PLP Antibodies and Age among cases.

\begin{tabular}{llllll}
\hline & N & Minimum & Maximum & Mean & Std. Deviation \\
\hline Age & 50 & 35 & 94 & 61.12 & 14.655 \\
\hline
\end{tabular}

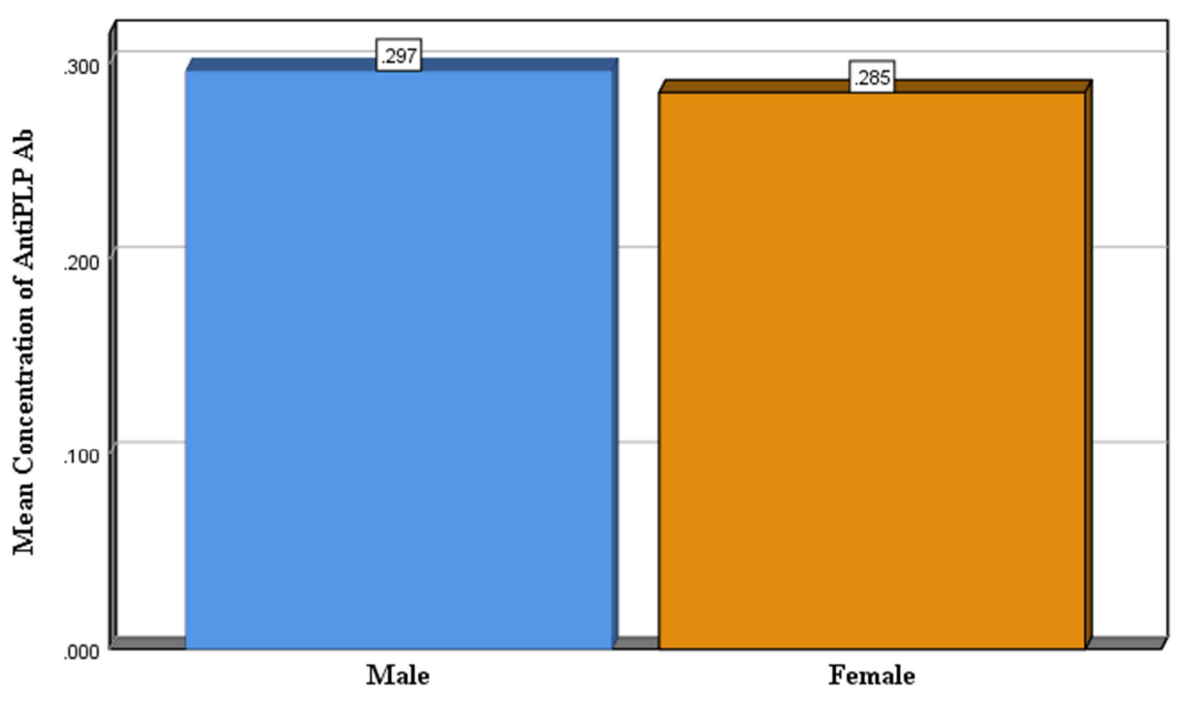

Gender

Figure 2. Mean concentration of antiphospholipid antibody status.

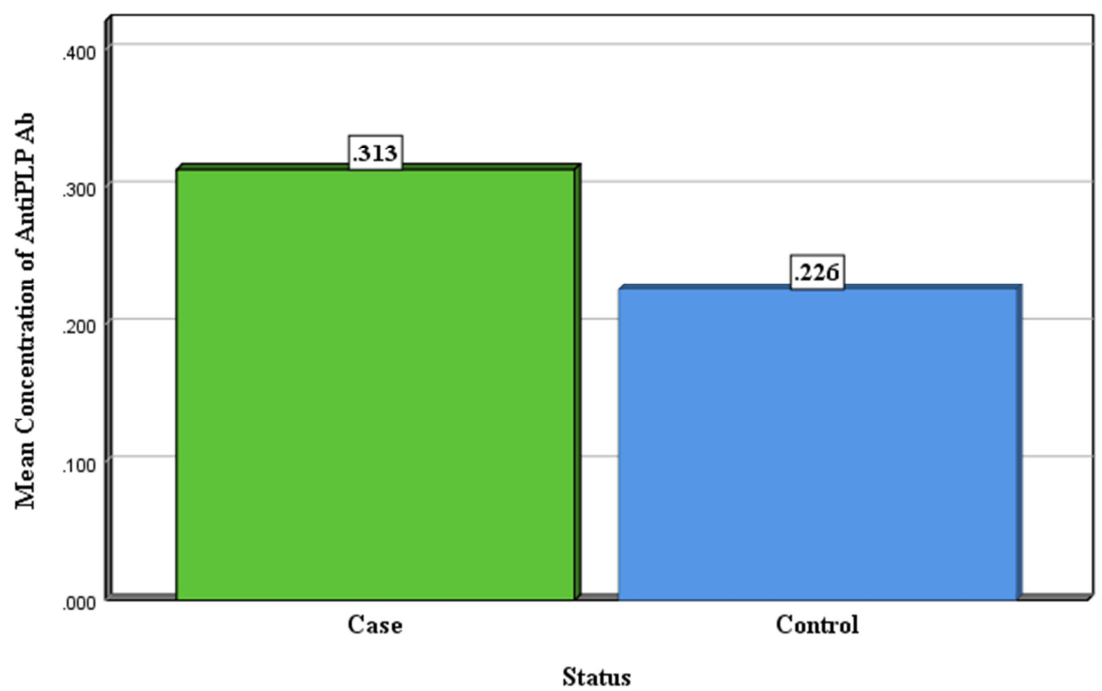

Figure 3. Mean concentration of antiphospholipid antibody gender. 


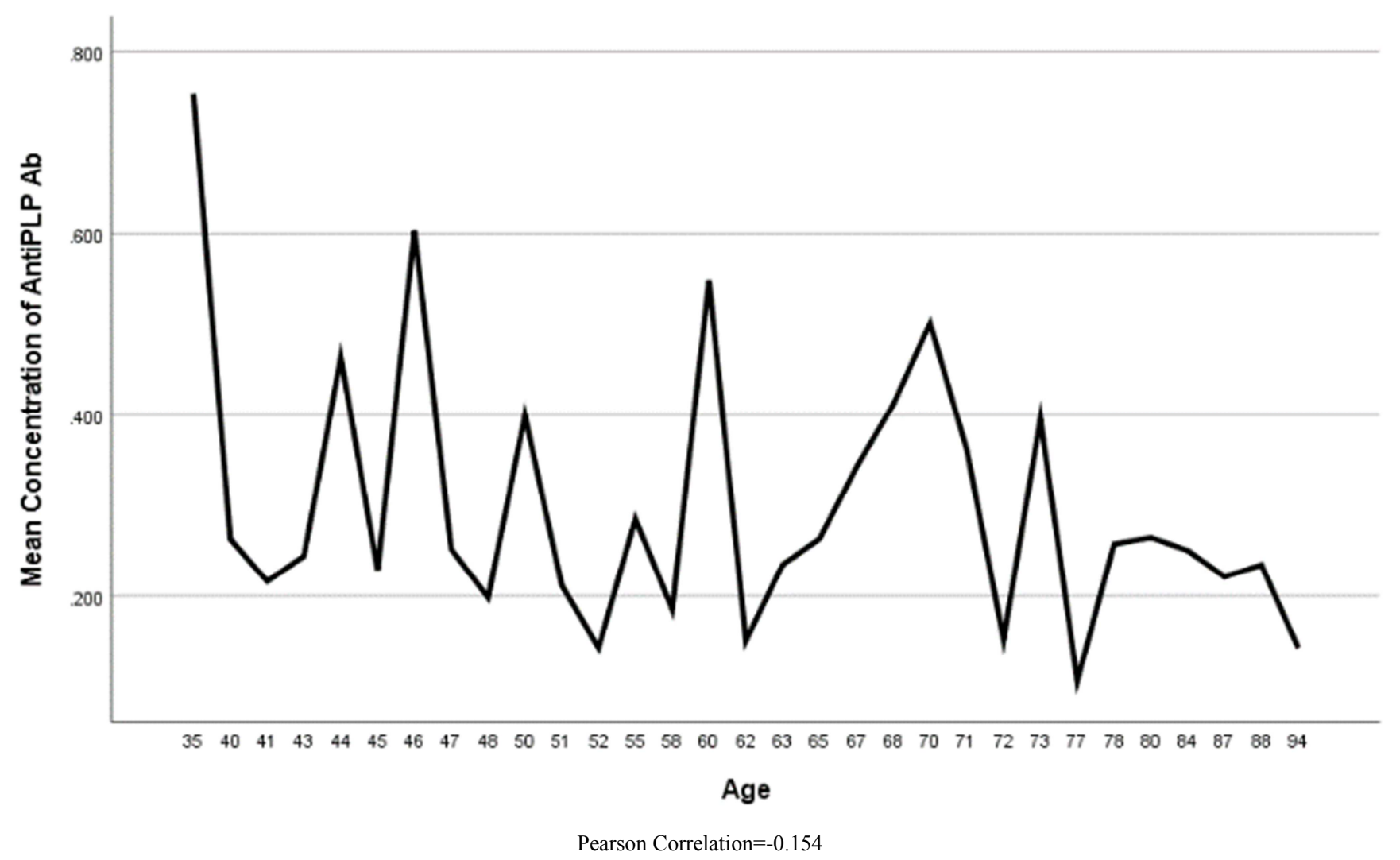

Figure 4. Describes the correlation between mean concentration of anti PLP and age of cases.

\section{Discussion}

Antiphospholipid antibody syndrome (APS) is a group of disorders related to both venous and arterial thromboembolic disease, which result in hypercoagulable state and increase the frequency of acute myocardial infarction (AMI) mainly in childhood [1, 2, 14]. This study was descriptive case controlled study done in yastabsheroon hospital in Khartoum state from (November 2020 to January 2021) to evaluate antiphospholipid antibody in myocardial infraction patients. Fifty (50) case and fifty (50) healthy individual group had been selected. The study found mean between patient with myocardial infraction (0.293) and control $(0.226)$ and the $(P$ value) is $(0.042)$. results of this study were agreed with several studies have addressed the effect of anti PLP anti body on coronary artery disease. In study of Y. Alder et al (1995), who reported an increased titer of four different aPL that detected in $6.9 \%$ of AMI hospitalized patients, mainly in men of younger age group [8], in other study done by $O$ Vaarala et al (1998), the study was show an increased levels of antiphospholipid antibodies in myocardial infarction (MI) patients. These findings suggest that MI may developed as a result of the presence of antiphospholipid antibodies [9]. In other study of Rolf Urbanus et al (2009), they reported that Lupus anticoagulant was detected six $(3 \%)$ patient with myocardial infarction patients [10], and in study curried out by J. Font et al study (2000) they reported that antiphospholipid antibodies (aPL) is associated with a variety of cardiac manifestations, in patients with systemic lupus erythematosus (SLE) and the "primary" antiphospholipid syndrome (APS) [11].

Linda Lóczi. et al (2020), they reported that in APS patients the risk of MI is considerable and MI may be the first manifestation of the disease and mostly affect the young ages [12].

Abid L, et al, (2011) concluded that Primary antiphospholipid syndrome should be considered as a cause of acute myocardial infarction in young adults [13].

Jean-Philippe Riga, et al. (2019), they reported that the microvascular myocardial infarction caused by antiphospholipid syndrome [15].

\section{Conclusion}

The presence of a specific Igm anti PLP antibody was contributed to an increased risk of venous and arterial thrombosis, particularly primary arterial thrombosis. In the current study, and according to $\mathrm{P}$ value the result show relationship between Anti PLP antibody and myocardial infraction and that agreed with previous studies.

Acknowledgement: First of all, thanks for Allah almighty for helping us to complete this work. And Thanks to my Supervisor Dr. Ehab Mohamed ElMadenahfor the useful comments, remarks, and engagement through the learning process of this thesis and for the continuous support from the initial to the last stage that enabled us to develop an understanding of the subject. and special Thank Alzaytouna specialist hospital to help me to make samples and thanks to 
each hospital that made it easy for me to collect the sample. And for all the patients' people from Whom, the Blood Samples Have been collected.

\section{References}

[1] Nazir S, Tachamo N, Lohani S, Hingorani R, Poudel DR, Donato A. Acute myocardial infarction and antiphospholipid antibody syndrome: a systematic review. Coron Artery Dis. $2017 \quad$ Jun; $28 \quad$ (4): 332-335. doi: 10.1097/MCA.0000000000000476. PMID: 28225386.

[2] Varner CK, Marquardt CW, Pickens PV. Antiphosphatidylserine Antibody as a Cause of Multiple Dural Venous Sinus Thromboses and ST-Elevation Myocardial Infarction. Am J Case Rep. 2018; 19: 1042-1046. Published 2018 Aug 31. doi: 10.12659/AJCR.909698.

[3] Ayan M, Alshebani Y, Tantoush H, Salih M, Abusnina W, Khaddr M, Smer A. Acute myocardial infarction in a young man with large left ventricular thrombus and the antiphospholipid syndrome. Proc (Bayl Univ Med Cent). 2018 Nov 13; $32 \quad$ (1): $110-112 . \quad$ doi: 10.1080/08998280.2018.1503479. PMID: 30956601; PMCID: PMC6442880.

[4] Tidsskr Nor Laegeforen. Role of phospholipids in hemostasis 1993 Aug 10; 113 (18): 2238-41. PMID: 8362386.

[5] Sletnes KE. Fosfolipidenesrolleihemostasen [Role of phospholipids in hemostasis]. Tidsskr Nor Laegeforen. 1993 Aug 10; 113 (18): 2238-41. Norwegian. PMID: 8362386.

[6] Shruti Chaturvedi and Keith R. McCrae. The antiphospholipid syndrome: still an enigma (2016 May 24) doi: 10.1182/asheducation-2015.1.53. PMCID: PMC4877624 NIHMSID: NIHMS786511 PMID: 26637701.

[7] Semczuk-Kaczmarek K, Platek AE, Ryś-Czaporowska A, Szymanski FM, Filipiak KJ. Acute Myocardial Infarction Due to Antiphospholipid Syndrome - Case Report and Review of the Literature. Curr Probl Cardiol. 2021 Mar; 46 (3): 100552. doi: 10.1016/j.cpcardiol.2020.100552. Epub 2020 Feb 20. PMID: 32216971.

[8] Y. Adler, Y. Finkelstein, G. Zandeman-Goddard, M. Blank, M. Lorber, A. Lorber, D. Faden, Y. Shoenfeld Lupus, et al The presence of antiphospholipid antibodies in acute myocardial infarction Review Article (Aug 1, 1995) vol. 4, 4: pp. 309-313.

[9] Vaarala, Department of Biochemistry, National Public Health Institute, Helsinki, Finland Antiphospholipid antibodies and myocardial infarction Review Article (February 1, 1998) Vol 7, Issue 2_suppl.Sega journals.

[10] Rolf T Urbanus PhD, Bob Siegerink MSc, Mark Roest PhD, Frist R Rosendaal MD, Philip G de Groot Phd, Ale Algra MD, et al (2009 Nov; 8) The Lancet Neurology Volume 8, Pages 998-1005.

[11] J. Font, R. Cervera, et al Cardiac Manifestations in the Antiphospholipid Syndrome (2000)- Hughes Syndrome pp 3242| Cite a978-1-85233-232-7.

[12] Lóczi L, Kappelmayer J, Tarr T, Bagoly Z. Antiphospholipid syndrome and the risk of myocardial infarction: current evidence and uncertainties. Kardiol Pol. 2020 Jan 24; 78 (1): 6-14. doi: 10.33963/KP.15090. Epub 2019 Dec 6. PMID: 31808421 .

[13] Abid L, Frikha F, Bahloul Z, Kammoun S. Acute myocardial infarction in young adults with antiphospholipid syndrome: report of two cases and literature review. Pan Afr Med J. 2011; 8: 13. doi: 10.4314/pamj.v8i1.71062.

[14] Polytarchou K, Varvarousis D, Manolis AS. Cardiovascular Disease in Antiphospholipid Syndrome. Curr Vasc Pharmacol. 2020; $18 \quad$ (6): 18 538-548. 10.2174/1570161117666190830101341.PMID:31530257.

[15] Riga JP, Leone A, Lambot F, Cappeliez O, Friart A. A microvascular myocardial infarction in a 16-year-old girl with antiphospholipid syndrome: a case report. Acta Clin Belg. 2019 Oct; 74 (5): 351-354. doi: 10.1080/17843286.2018.1516182. Epub 2018 Aug 30. PMID: 30160190 . 